Rio de Janeiro. Ano 15. Volume 22. Número 3. Setembro a Dezembro de 2021 Periódico Quadrimestral da Pós-Graduação Stricto Sensu em Direito Processual da UERJ

Patrono: José Carlos Barbosa Moreira (in mem.). ISSN 1982-7636. pp. 143-169 www.redp.uerj.br

\title{
EVOLUÇÃO DA TÉCNICA PROCESSUAL DO INDIVIDUALISMO \\ EXACERBADO AO COLETIVISMO ARTIFICIAL: O IRDR COMO FERRAMENTA DE EQUILÍBRIO DO SISTEMA ${ }^{1}$
}

PROCEDURAL TECHNIQUES EVOLUTION FROM EXACERBATED INDIVIDUALISM TO ARTIFICIAL COLLECTIVISM: IRDR AS THE SYSTEM

BALANCE TOOL

Bruno Dantas

Ministro do Tribunal de Contas da União (TCU). Pós-Doutor em Direito pela UERJ, Doutor e Mestre em Direito pela PUCSP. Pesquisador visitante na Benjamin N. Cardozo School of Law (Nova York, EUA), no Max Planck Institute for Regulatory Procedural Law (Luxemburgo) e no Institute de Recherche Juridique da Universidade Paris 1 PanthéonSorbonne. Professor Titular do Mestrado e Doutorado em Direito da UNINOVE. Professor Associado do Mestrado e Doutorado em Direito da Regulação da FGV-Direito Rio. Professor-Adjunto da Graduação, Mestrado e Doutorado em Direito da UERJ. Brasília/DF e Rio de Janeiro/RJ. E-mail: dantasbruno@outlook.com

Caio Victor Ribeiro dos Santos Mestrando em Direito Processual pela Universidade do Estado do Rio de Janeiro (UERJ). Pós-graduado em Direito Processual Civil pelo Instituto Brasiliense de Direito Público (IDP). Professor convidado da pós-graduação lato sensu da Universidade do Estado do Rio de Janeiro (UERJ). Assessor de Ministro do Tribunal de Contas da União (TCU). Brasília/DF e Rio de Janeiro/RJ.

\footnotetext{
${ }^{1}$ Artigo recebido em 13/05/2021 e aprovado em 09/06/2021.
} 
RESUMO: O artigo demonstra que o Incidente de Resolução de Demandas Repetitivas (IRDR) ofereceu um caminho procedimentalmente mais promissor do que puderam as ações coletivas do art. 81, inciso III do Código de Defesa do Consumidor no que diz respeito à tutela dos direitos individuais homogêneos, sendo capaz de alinhar economia de escala e preservação da autonomia da vontade onde aquelas ainda falham. Ao final, sustenta-se haver entre as duas ferramentas uma relação mista: de complementariedade para a tutela de pretensões inexpressivas, e de superioridade do IRDR para a tutela de pretensões suficientemente expressivas a justificar o exercício do direito de ação.

PALAVRAS-CHAVE: incidente de resolução de demandas repetitivas; tutela pluriindividual; tutela coletiva; litigiosidade de massa; acesso à justiça; autonomia individual;

ABSTRACT: This paper demonstrates that the Repetitive Claims Resolution Proceeding (IRDR) has provided a procedurally more auspicious technique for the resolution of mass claims regarding homogeneous individual rights than the article 81, item III of the Consumer Protection Code class actions were able to, for it affords economy of scale without violating litigants autonomy in mass adjudication. At the end, it argues that there is a mixed relationship between class actions and IRDR: a complementary one between both techniques for the protection of negative value claims, and a superiority one, favoring the latter, for the protection of positive value claims.

KEYWORDS: Repetitive Claims Resolution Proceeding; multi-party litigation; collective redress; mass litigation; access to justice; litigants autonomy.

\section{Introdução}

Nenhum sistema de justiça pode se afirmar justo se falha no oferecimento de técnicas procedimentais adequadas para a realização dos direitos substanciais ${ }^{2}$. Os procedimentos,

\footnotetext{
${ }^{2}$ CANOTILHO, J. J. Gomes. Constituição e défice procedimental. In Estudos sobre direitos fundamentais.
} $1^{\mathrm{a}}$ ed. São Paulo: RT, 2008. 
aliás, são dimensão indissociável dos direitos fundamentais, como explica Robert $\mathrm{Alexy}^{3}$, e da própria teoria da justiça, segundo John Rawls ${ }^{4}$. "No remedy no right”, costumam dizer os ingleses, mas há muito já o diziam os antigos romanos ${ }^{5}$.

De fato, as últimas décadas vêm sendo marcadas por uma ampla reestruturação de pressupostos que há muito foram aceitos pela ciência do direito processual. Trata-se de uma reformulação tão expressiva que alcança não apenas aspectos procedimentais, mas, como anota Humberto Dalla, o próprio eixo metodológico da jurisdição ${ }^{6}$, que já não reflete integralmente os mesmos aspectos que nela identificavam Chiovenda, Carnelutti ou Allorio, cujos conceitos já há algum tempo parecem insuficientes para tratar do tema.

As profundas implicações dessa renovação metodológica se fizeram sentir no Brasil nas inúmeras reformas sediadas desde o final do século passado até recentemente, com o Código de Processo Civil de 2015 (CPC), do que não decorre que neste se esgotem.

O que nelas se nota, vale pontuar, além de uma dificuldade do direito processual em trabalhar com novas variáveis utilizando as mesmas categorias que lhe foram legadas pela tradição, é uma preocupação crescente com a litigiosidade serial, na qual se evidenciam os interesses individuais homogêneos, que embora sejam essencialmente individuais ${ }^{7}$ e pudessem ser tutelados pela via tradicional do processo, por respeito ao direito a um

\footnotetext{
${ }^{3}$ ALEXY, Robert. Teoria dos Direitos Fundamentais. Trad. Virgílio Afonso da Silva. São Paulo: Malheiros, 2008. p. 470-498.

${ }^{4}$ RAWLS, John. Uma teoria da justiça. Trad. Almiro Pisetta e Lenita M. R. Esteves. São Paulo: Martins Fontes, 1997, p. 89-101.

${ }^{5}$ CAPPELLETI, Mauro. O acesso à justiça e a função do jurista em nossa época. Revista de Processo. vol. 61, 1991, p. 8.: ". Esta "positivação do direito natural" levou de qualquer modo, à supressão do antigo conflito entre direito natural e direito positivo, o primeiro tido como eterno universal, não obstante de fato, muito mais privado de tutela e ainda de efetividade - no remedy no right, como disseram realisticamente aos ingleses, mas primeiro já haviam dito os antigos romanos.".

${ }^{6} \mathrm{PINHO}$, Humberto Dalla Bernardina de. A releitura do princípio do acesso à justiça e o necessário redimensionamento da intervenção judicial na resolução dos conflitos na contemporaneidade". In Revista Jurídica Luso-brasileira. Ano 5. Número 3. 2019, p. 262. Ada Pellegrini, em sua última obra em vida, deixou um novo conceito de jurisdição, este considerando a justiça consensual. Cf. GRINOVER, Ada Pellegrini. Ensaio sobre a processualidade: fundamentos para uma nova teoria geral do processo. Brasília: Gazeta Jurídica, 2016, p. 30: "na atualidade, não é mais poder, mas apenas função, atividade e garantia. Seu principal indicador é o acesso à Justiça, estatal ou não, e seu objetivo, o de pacificar com justiça. Este conceito de jurisdição abrange a justiça estatal, a justiça arbitral e a justiça conciliativa".

${ }^{7}$ BARBOSA MOREIRA, José Carlos. Ações coletivas na Constituição de 1988. Revista de Processo, São Paulo: Editora Revista dos Tribunais, v. 16, n. 61, jan./mar. 1991, p. 187.
} 
procedimento adequado $^{8} \mathrm{e}$ à necessidade de imprimir eficiência à resolução dos casos repetitivos, foram equipados com técnicas diferenciadas de tutela ${ }^{9}$.

O objetivo deste artigo é analisar o Incidente de Resolução de Demandas Repetitivas (IRDR) do ponto de vista de sua relevância para a consolidação de um sistema de justiça processual mais efetivo e adequado à tutela dos direitos individuais homogêneos. Ao alinhar economia de escala com a preservação da autonomia individual, o CPC de 2015, com o IRDR, ofereceu um caminho procedimentalmente mais promissor do que as ações coletivas do art. 81, inciso III do CDC puderam no que tange à tutela dos direitos individuais homogêneos - ponto do qual nos ocuparemos ao final.

Para chegar lá, demonstrar-se-á que quatro, pelo menos, foram os fatores que pavimentaram o caminho para a adoção do IRDR pelo legislador do CPC 2015: (i) a mudança de paradigma quanto ao fundamento individualista do direito processual civil clássico; (ii) o movimento do acesso à justiça; (iii) o movimento das tutelas diferenciadas; e (iv) a experiência norte-americana com o declínio da class action indenizatórias.

\section{O direito processual diante de novos paradigmas e renovados objetivos}

Desde as clássicas discussões que se leciona nas cátedras de teoria geral, o direito processual vem sendo objeto de constantes metamorfoses impulsionadas por um número crescente de estudiosos da matéria.

Um olhar topológico basta para visualizar dois momentos bem distintos na história mais recente do direito processual, cuja divisão, embora hoje possa parecer óbvia, nem sempre o foi, e não raro continua sem o ser, conforme deixam transparecer aqui e ali certos

\footnotetext{
${ }^{8}$ A relação do que Canotilho chama de 'déficit procedimental' com a criação do Incidente de Resolução de Demandas Repetitivas foi explorada por um dos autores deste artigo em DANTAS, Bruno. Teoria dos Recursos Repetitivos: tutela pluri-individual nos Recursos Dirigidos ao STF e ao STJ (art. 543-B e 543C do CPC). São Paulo: Editora Revista dos Tribunais), 2014. A esse respeito, cf. Alexy, Op. cit, p. 474.: "Direitos a procedimentos podem ser tanto direitos à criação de determinadas normas procedimentais quanto direitos a uma determinada 'interpretação e aplicação concreta' de normas procedimentais. Um exemplo desse último caso são as inúmeras decisões do Tribunal Constitucional Federal acerca das normas sobre leilão judicial, cujo tema é a interpretação de normas procedimentais conforme à Constituição. O direito a procedimentos como direito a proteção jurídica efetiva, nesse caso, tem como destinatário os tribunais. De outra parte, os direitos a procedimentos que têm como objeto a criação de normas procedi mentais, por serem direitos ao estabelecimento de normas, têm como destinatário o legislador."

${ }^{9}$ NUNES, Dierle. Novos rumos para as tutelas diferenciadas no Brasil? In: THEODORO JÚNIOR, Humberto; LAUAR, Maira Terra. Tutelas diferenciadas como meio de incrementar a efetividade da prestação jurisdicional. Rio de Janeiro: GZ Editora, 2011., p. 25-52.
} 
debates doutrinários: de um lado, uma ciência processual orientada à exaltação de sua própria autonomia, de outro, uma orientada à efetivação dos direitos substanciais.

A pretensão de cientificidade, fruto de uma tentativa dos estudiosos do direito de importar a metodologia das ciências exatas ${ }^{10}$, se teve o mérito de alavancar $o$ desenvolvimento teórico de todo um tecido conceitual próprio em certas áreas, teve a desventura de colocar, aqui e ali, obstáculos teóricos de difícil superação. Da cognição sumária $^{11}$ à tutela coletiva ${ }^{12}$, o direito processual é farto em exemplos nesse sentido.

O extenso histórico de reformas processuais no Brasil, além de revelar a tentativa de adequação das técnicas a um novo paradigma, sinaliza também, pela tendência nelas impressa, que alçar a efetividade do direito material como objeto central do direito processual em nada fragiliza sua autonomia, senão revela sua verdadeira natureza.

Discorramos inicialmente sobre o primeiro aspecto, o da mudança de paradigma.

\subsection{Mudança de paradigma: a tutela jurisdicional entre $o$ fundamento individualista clássico e os interesses da esfera social e pública.}

A estrutura conceitual do direito processual civil foi eminentemente construída sobre as premissas de um paradigma político-filosófico hoje em transição; se não em transição, que incorpora novos valores e, portanto, dilata-se, em relação ao anterior.

Para os fins deste artigo, não é necessário perscrutar com profundidade os alicerces filosóficos e políticos do Estado liberal ${ }^{13}$, bastando o registro de que ele guarda em sua essência um fundamento individualista, conforme anota Bobbio ${ }^{14}$.

\footnotetext{
${ }^{10}$ SILVA, Ovídio A. Batista. Processo e ideologia: o paradigma racionalista. Rio de Janeiro: Forense, 2004.

${ }^{11}$ SCHENK, Leonardo Faria. Contraditório e cognição sumária. Revista eletrônica de direito processual. v. 13, n. 13, 2014, p. 553: "A opção pela cognição sumária tem alterado as estruturas do processo civil, rompendo com o modelo padrão que liga a jurisdição de conhecimento à necessária formação da coisa julgada."

${ }^{12}$ BASTOS, Fabrício Rocha. Interface entre o CPC 15 e os Processos Coletivos. Revista do Ministério Público do Rio de Janeiro no 70, out./dez. 2018, p. 128: "Esse dispositivo [art. 76 do Código Civil de 1916] foi um obstáculo a qualquer demanda que trouxesse repercussão transindividual, vez que permitia tão somente o exercício do direito de ação para a tutela de interesses meramente individuais."

${ }^{13}$ Paulo Bonavides (Do Estado liberal ao Estado social. 8. ed. São Paulo: Malheiros, 2007. p. 67-68) afirma: "Quem participava essencialmente na formação da vontade estatal em face do novo Estado liberaldemocrático? A burguesia, sem dúvida, a cuja sombra, em nome do povo, se ocultavam interesses parcelados da classe dominante (...). A burguesia precisava de liberdade, e o Estado liberal-democrático, assentado naquele formalismo jurídico que em Kant chegara à sua formulação mais acabada, era um Estado destituído de conteúdo, neutralizado para todo ato de intervenção que pudesse embaraçar a livre iniciativa material e espiritual do indivíduo, o qual, como soberano, cingira a Coroa de todas as responsabilidades sociais".

${ }^{14}$ BOBBIO, Norberto. A era dos direitos. Trad. Carlos Nelson Coutinho. Rio de Janeiro: Elsevier, 1992. p. 59
} 
Esse fundamento individualista foi responsável pela estruturação de todo o sistema jurídico moderno a partir da noção de direito subjetivo de matriz lockeana ${ }^{15}$ e hobbesiana ${ }^{16}$.

A estrutura essencialmente individualista do direito burguês que emergiu da Revolução Francesa atraía, como não poderia deixar de ser, um modelo igualmente individualista do direito processual civil ${ }^{17}$.

Se, por um lado, o direito civil era o locus da regulamentação jurídica da circulação de riquezas (obrigações, contratos, direitos reais), o direito processual, por sua vez, não era senão a ferramenta necessária - e refinada, do ponto de vista da dignidade humana e dos avanços civilizatórios - à proteção desses interesses.

A marcha do século XX na direção do Estado Social fez com que o pêndulo da tutela jurisdicional se deslocasse do campo estritamente individual para o coletivo.

A ascensão dos direitos de terceira geração no Brasil repercutiu amplamente na seara do direito processual civil, tendo ensejado uma grande efervescência na comunidade jurídica. Como aponta Cappelletti, a massificação da sociedade tem nos levado a perceber que não assiste mais razão à tentativa de insistir que o direito cuide apenas de relações jurídicas travadas entre indivíduo e indivíduo, ou entre indivíduo e Estado. A realidade de hoje é bem mais complexa: há, entre o indivíduo e o Estado, uma série de grupos, comunidades e coletividades que reclamam a tutela de direitos e não são nem totalmente individuais, nem totalmente públicos - os quais expressam muito bem os desafios da sociedade contemporânea com os quais a tutela jurisdicional deve lidar ${ }^{18}$.

\footnotetext{
${ }^{15}$ Cf. Bobbio (Idem, ibidem): "Precisamente partindo de Locke, pode-se compreender como a doutrina dos direitos naturais pressupõe uma concepção individualista da sociedade e, portanto, do Estado, continuamente combatida pela bem mais sólida e antiga concepção organicista, segundo a qual a sociedade é um todo, e o todo está acima das partes".

${ }^{16}$ Cf. VILLEY, Michel. A formação do pensamento jurídico moderno. Trad. Claudia Berliner. São Paulo: Martins Fontes, 2005. p. 705:.

${ }^{17}$ Nesse sentido, Barbosa Moreira (A ação popular do direito brasileiro como instrumento de tutela jurisdicional dos chamados "interesses difusos". In Temas de direito processual civil. São Paulo: Saraiva, 1977, p. 110): "tem sabor de lugar-comum a observação de que a estrutura clássica do processo civil, tal como subsiste na generalidade dos ordenamentos de nossos dias, corresponde ao modelo concebido e realizado para acudir fundamentalmente a situações de conflito entre interesses individuais"

${ }^{18} \mathrm{Cf}$. CAPPELLETTI, Mauro. Vindicating the Public Interest through the Court's (1976) 25 Buffalo Law Review, 649, number 3, article 2, p. 649: "This "proprietary" concept of rights and locus standi is very clear and simple in the civil law tradition-indeed, much too simple to reflect present realities. The Classic Roman summa divisio between "public" and "private"' 7 has become, as incisively stated by a British observer, a "mighty cleavage" with no connecting bridges-or intermediaries-between the two aspects of the dichotomy: the individual and the state. Today's reality, however, is much more complex and pluralistic than that abstract dichotomy: between the individual and the state there are numerous groups, communities, and collectivities
} 
Essa mudança de paradigma, porém visualizada menos pelo movimento individualsocial e mais pelo privado-público, já vinha se expressando em outros lugares do mundo, como nos Estados Unidos, e foi notada por Abram Chayes, que a demonstrou no seu clássico artigo publicado em 1976, "The Role of Judge in Public Litigation".

A ideia central de Abram Chayes era contrastar o modelo tradicional e individualista de tutela jurisdicional com o novo modelo que emergia, a partir da década de 1950, na prática das Cortes federais daquele país. Nesse artigo, o professor de Harvard identificou cinco características da tutela jurisdicional tradicional: (i) as ações possuíam dois polos; (ii) a tutela jurisdicional era retrospectiva; (ii) o direito e a tutela jurisdicional eram interdependentes; (iii) as ações tinham tudo que precisavam (self-contained episode); (v) o processo era iniciado pelas partes e por elas controlado ${ }^{19}$.

Em contrapartida, descrevia o novo modelo de litigância como extensa e amorfa ("sprawling and amorphous"), sujeita a mudanças durante o curso do processo ("subject to change over the course of the litigation" e impregnado e misturado com negociações e mediações em diversos pontos ("suffused and intermixed with negotiating and mediating processes at every point") sendo o juiz uma figura com posição central na organização e gerenciamento do caso. Daí por que, mais tarde, Judith Resnik vai escrever Managerial Judges (1983), detalhando as então recentes mudanças no papel tradicional do juiz ${ }^{20}$.

Como exemplo do tipo de litígio com que lida a tutela processual nesse novo paradigma, citava as ações que pleiteavam a dessegregação de escolas, que discutiam discriminação no ambiente de trabalho ou o direito de prisioneiros à reformulação do sistema penitenciário, bem como fraude envolvendo consumidores, fraude envolvendo o mercado de capitais, direito antitruste, falência, defesa do meio ambiente, entre outros, todos expressando, em certo grau, um modelo público de processo ${ }^{21}$.

Seja do ponto de vista individual-social ou do ponto de vista privado-público, fato é que o processo civil passa por uma redefinição de certos fundamentos. Nesse novo modelo, que não diminui (e nem pode diminuir) a importância do indivíduo (com redefinição não

\footnotetext{
which forcefully claim the enjoyment and judicial protection of certain rights which are classifiable neither as "public" nor "private" in the traditional sense."

${ }^{19}$ CHAYES, Abram. The Role of the Judge in Public Law Litigation. 89 HARV. L. REV. 1281, 1976, p. 1283.

${ }^{20}$ RESNIK, Judith. Managerial Judges. 96 Harv. L. Rev. 374, 448, 1982.

${ }^{21}$ BOBBIO, Op. cit. p.
} 
dizemos eliminação do antigo, mas atualização ao novo), os interesses individuais passam a conviver, no palco do processo, com outros valores relevantes para a jurisdição, estes advindos das esferas social e pública, e que adquirem crescente densidade normativa ${ }^{22}$.

\subsection{O movimento do acesso à justiça e das tutelas diferenciadas}

O fenômeno da reestruturação das bases do direito processual como consequência da adequação da técnica processual às nuances da sociedade atual pode ser abordado por inúmeros pontos de vista. Dois deles, entretanto, muito conexos, nos parecem concorrer diretamente para a metamorfose que mais tarde vai dar origem ao IRDR.

Em primeiro lugar, ele pode ser examinado do ponto de vista do movimento do acesso à justiça, que encontrou em Cappelletti seu grande precursor.

O movimento de universalização e multiplicação dos direitos do homem após a Segunda Guerra Mundial, como demonstrou Bobbio em seu clássico A Era dos Direitos, revelou a insuficiência da caixa de ferramentas processuais tradicional para a tutela de novos bens, sujeitos de direitos e status dos indivíduos ${ }^{23}$. Faltavam instrumentos. O pontapé dado pelo Projeto Florença, nesse aspecto, foi indispensável tanto para a disponibilização de técnicas procedimentais para a tutela dos direitos transindividuais, resultado da segunda onda, como pelo impulso à elaboração de métodos mais simplificados e adequados para a tutela processual, resultado da terceira onda.

Cappelletti, ao apresentar em 1976 a obra coletiva La tutela degli interessi diffusi nel diritto comparato: con particolare riguardo alla protezione dell'ambiente e dei consumatori, esclarecia que diante das agressões a bens ou interesses coletivos que caracterizavam a sociedade moderna "l'ottica individualistica si rivela del tutto inadeguata, e inutilizzabile diventa quell'arsenale di metodi e di concetti di cui il giurista

\footnotetext{
${ }^{22}$ Essa, aliás, é a lição de Arruda Alvim: "O processo civil de nossos dias encontra-se num estágio de modificação profunda, na mesma esteira do que precedentemente se tem verificado no mundo ocidental, consistente em colocar ao lado do que se pode designar como processo civil clássico (em sua estrutura) outros instrumentos, destinados a fazer frente às necessidades, que não datam de hoje, mas que são cada vez mais agudas, nestes dias contemporâneos, conduzindo a uma espécie de convivência entre o processo civil clássico (já, em si mesmo, intrinsecamente alterado, em decorrência do descarte da inspiração individualista radical) e esse novo aparato hodierno" (grifos nossos) (ARRUDA ALVIM, José Manoel de. Anotações sobre as perplexidades e os caminhos do processo civil contemporâneo. Disponível em http://bit.ly/1ba78kp. Acesso em 13/4/2021, p. 7).

${ }^{23}$ BOBBIO, Op. cit. p. 33.
} 
tradizionalmente dispone e che è, quasi sempre, informato al canone dell'individuale" ${ }^{24}$. Essa observação, contemporânea às de Chayes nos EUA, iria afetar profundamente a tutela jurisdicional nos anos seguintes, inclinando-a para uma adequação às novas categorias de direito material mais afetas a uma dimensão social-coletiva.

Surge, com o Projeto Florença, na esteira da segunda onda do acesso à justiça, a necessidade de se pensar nas ações coletivas para conferir justiciabilidade aos direitos de grupo e coletividades, que, pela ótica tradicional do processo civil individualista, não seriam - se é que sequer poderiam ser, em certos casos - adequadamente tutelados ${ }^{25}$.

Também é possível visualizar esse fenômeno do ponto de vista do movimento das tutelas diferenciadas, fruto do impulso dado pela doutrina italiana da década de 1970, que teve em um trabalho publicado por Proto Pisani seu marco inicial ${ }^{26}$.

Referindo-se aos procedimentos especiais e às formas típicas de tutela sumária, num momento em que o direito processual relutava em admitir restrições cognitivas e técnicas diversas das do procedimento comum, o também professor da Universidade de Florença, quando Cappelletti já se ocupava menos de questões técnicas do processo e mais de seus elementos socioculturais, chamou atenção para a necessidade de se dispor de modelos processuais "delineados com a intenção de se garantir as mais idôneas formas de tutela para as várias categorias de situações jurídicas merecedoras de tutela jurisdicional, aludindo à tutela jurisdicional diferenciada (tutela giuridizionale differenziata), que mais tarde influenciaria profundamente a doutrina no Brasil. ${ }^{27}$

Proto Pisani buscava, com a ideia de tutela diferenciada, viabilizar algum desvio de rota do procedimento comum para melhor atender às especificidades que certos litígios ${ }^{28}$ apresentavam, daí a ênfase aos procedimentos especiais e à cognição sumária.

\footnotetext{
${ }^{24}$ CAPPELLETTI, Mauro. La tutela degli interessi diffusi nel diritto comparato: con particolare riguardo alla protezione dell'ambiente e dei consumatori. Milano: Giuffrè, 1976, p. VII.

${ }^{25}$ CAPPELLETTI, Mauro; GARTH, Bryant. Acesso à Justiça. Tradução Ellen Gracie Northfleet. Porto Alegre: Fabris, 1988. p. 50.

${ }^{26}$ PISANI, Andrea Proto. Tutela giurisdizionale differenziata del lavoro. Milano: Giuffré, 1977.

${ }^{27}$ NUNES, Op. cit., p. 25-52.

${ }^{28}$ Importante destacar que o tipo de litígios para os quais Proto Pisani propunha essa diferenciação procedimental eram os mesmos em torno dos quais se estruturou toda a nossa dogmática clássica. Isto é, se referia a litígios individuais. A diferenciação procedimental para os litígios coletivos vai ocupar mais o pensamento de Cappelletti, como ficou claro com as conclusões do Projeto Florença.
} 
A bem da verdade, Nicòlo Trocker explica que a ideia de uma tutela jurisdicional diferenciada teria surgido em 1955, embora atrelada ao estudo da jurisdição constitucional, quando Cappelletti publica o texto La giurisdizione constituzionale dele libertà ${ }^{29}$.

Num período em que as Constituições eram ainda "um prelúdio do céu", um "conjunto de proposições filosóficas", explica o italiano, Cappelleti notou que os direitos fundamentais reconhecidos pelas Constituições emergentes não poderiam ficar à mercê da solução meramente abstrata do texto constitucional, tampouco da disposição positiva da Administração Pública, devendo a efetivação desses direitos passar pela jurisdição, isto é, ser realizada por meio de garantias judiciais que viabilizassem sua plena proteção ${ }^{30}$.

Buscando testar sua hipótese, o ainda jovem erudito de Florença examina o art. $8^{\circ}$ da Declaração Universal dos Direitos do Homem e constata que a versão francesa falava em um direito a "un recours effectif", a versão inglesa em um "right to an effective remedy", e a versão alemã, por sua vez, em "Recht auf wirksamen Rechtsschutz" ${ }^{31}$ ". Daí extrai a fundamentação para sustentar que à previsão dos direitos fundamentais deveria corresponder instrumentos judiciais destinado à sua efetiva proteção.

As profundas implicações da ideia cappellettiana de tutela jurisdicional diferenciadas não serão captadas pela doutrina processual civil naquele momento, nesta vindo a surgir apenas mais tarde, e com outra conotação, com Proto Pisani.

Entretanto, destaca Trocker, a ideia de Cappelletti teve o grande mérito de evidenciar a hoje clara "estreita relação entre a estrutura dos direitos e sua forma de tutela processual" num momento em que esta vinha sendo largamente negligenciada, ou eclipsada, pela exaltação da autonomia do direito processual - paixão compartilhada pelas doutrinas processuais da primeira metade do século passado. ${ }^{32}$

Ambos os movimentos, o de acesso à justiça e o das tutelas diferenciadas, para além dos diversos pontos de contato, possuem em comum a nobre característica de terem (re)colocado a efetividade do direito material como foco da técnica processual. A

\footnotetext{
29 TROCKER, Op. cit. p.4 46.

${ }^{30}$ Ibid. p. 447.

${ }^{31}$ Ibid. p. 448.

32 TROCKER, Op. Cit. Cf.: 'Invece, il contributo dell'analisi cappellettiana che preme evidenziare in questo contesto è um altro e consiste nell'aver messo in luce um tema oggi di grande attualità, vale a dire, il tema dela stretta correlazione tra struttura dei diritti e forma di tutela processuale, largamente transcurato dalle dottrine processualistiche della prima metà del secolo orientate ed esaltare l'autonomia del processo rispetto al diritto sostanziale" (grifos nossos).
} 
Revista Eletrônica de Direito Processual - REDP.

Rio de Janeiro. Ano 15. Volume 22. Número 3. Setembro a Dezembro de 2021

Periódico Quadrimestral da Pós-Graduação Stricto Sensu em Direito Processual da UERJ

Patrono: José Carlos Barbosa Moreira (in mem.). ISSN 1982-7636. pp. 143-169

www.redp.uerj.br

instrumentalidade do processo é resultado não de um ou outro trabalho, mas de um corpo de ideias, tendo estas sido bastante influenciadas pela escola florentina, onde exerceram magistério dois importantes artífices do direito processual, tanto do ponto de vista endo quanto meta processual, como foram Cappelletti e Proto Pisani. Poder-se-ia dizer que a obra dos dois professores se complementa: enquanto o primeiro renovou a necessidade de fina aderência entre a técnica processual e as particularidades dos litígios de grupos $e$ coletividades, o segundo renovou a necessidade de fina aderência entre a técnica processual e as particularidades dos litígios individuais com os quais sempre se lidou. Dois enfoques, um mesmo objetivo: a efetividade da tutela do direito material.

O IRDR, visualizado por um ângulo mais amplo, é um mecanismo que se insere no contexto de ambos os movimentos: no do acesso à justiça, porque veio, como aponta Aluísio Mendes, complementar ${ }^{33}$ o papel das ações coletivas para a tutela dos direitos individuais homogêneos, representando, nesse sentido, um avanço que não é senão resultado do impulso inicial da segunda onda; e no de tutelas diferenciadas porque, como destaca Dierle Nunes, há pelo menos três tipos de litigiosidades: a individual (com a qual se ocupou Proto Pisani), a coletiva (com a qual se ocupou Cappelletti), e a serial (com a qual se ocupou o CPC 2015), sendo o Incidente de Resolução de Demandas Repetitivas uma técnica procedimental diferenciada desenhada para a realidade da última categoria ${ }^{34}$.

\footnotetext{
33 "Com a entrada em vigor do novo Código de Processo Civil, será acrescida ao ordenamento jurídico brasileiro a previsão de um processo incidente para corroborar a solução coletiva de conflitos, somando-se às ações coletivas e aos meios extrajudiciais de solução de conflitos coletivos. Ter-se-á, portanto, desejado sistema pluralista, porque, em primeiro lugar, nem sempre se está diante de uma ação coletiva, independente das razões para o seu não ajuizamento. Por outro lado, a realidade demonstra que nem sempre as ações coletivas ajuizadas foram capazes de conter uma grande quantidade de litígios, tendo em vista, por exemplo, a limitação do próprio pedido ou a legitimidade do autor. Do mesmo modo, a questão comum poderá advir não de direitos individuais homogêneos propriamente ditos, mas de pretensões variadas. Nesse sentido, o incidente de resolução de demandas repetitivas e as ações coletivas possuem sistemática procedimental diversa, mas um caráter complementar e de apoio, precipuamente se relacionado à economia processual e ao princípio da igualdade." MENDES, Aluisio Gonçalves de Castro; SILVA, Larissa Clare Pochmann da. Ações Coletivas e incidente de resolução de demandas repetitivas: algumas considerações sobre a solução coletiva de conflitos. RJLB, Ano 3, 2017., $\mathrm{n}^{\circ}$ 1, p. 158.

${ }^{34}$ Dierle escrevia em 2011 (Op. cit, p. 25-52) e falava ainda em um incidente de coletivização de pretensões isomórficas. Enquadrando essa ferramenta no contexto das tutelas diferenciadas, destacava a necessidade de criação de um ferramental adequado para lidar com a litigiosidade em massa ou de alta intensidade, que não se confunde nem com a individual, nem com a coletiva: "Não se pode negar a diversidade de litigiosidade existente na atualidade, que poderia se dividir em três grandes grupos: (a) individual ou 'de varejo': sobre a qual o estudo e a dogmática foram tradicionalmente desenvolvidos, envolvendo alegações de lesões e ameaças de direito isoladas; b) a litigiosidade coletiva: envolvendo direitos coletivos, difusos e individuais homogêneos, nos quais se utilizam v.g, procedimentos coletivos representativos, normalmente patrocinados por legitimados extraordinários (órgãos de execução do MP, Associações representativas etc.) mediante as Class actions,
} 
Revista Eletrônica de Direito Processual - REDP.

Rio de Janeiro. Ano 15. Volume 22. Número 3. Setembro a Dezembro de 2021

Periódico Quadrimestral da Pós-Graduação Stricto Sensu em Direito Processual da UERJ

Patrono: José Carlos Barbosa Moreira (in mem.). ISSN 1982-7636. pp. 143-169

www.redp.uerj.br

\section{O papel da técnica processual diante da nova realidade}

O novo contexto surgido a partir da ascensão dos direitos sociais e da massificação dos litígios conduz, como já foi afirmado, à necessidade de ajustes na técnica processual.

Bedaque bem afirma que "as questões maiores do processo são solucionadas com dados inerentes à relação da vida e ao direito substancial que regula" ${ }^{35}$. Por isso, "quanto mais consciência tiver o processualista desse fenômeno, maiores serão as possibilidades de construção de mecanismos aptos a alcançar os escopos do processo"36.

Daí porque o estudioso do direito processual civil precisa ter sempre presente que, quando o instrumento falha, o objeto acaba sendo artificialmente esvaziado ${ }^{37}$.

Entendemos que, ao lado da possibilidade de proteção coletiva direitos individuais homogêneos, deve coexistir também uma técnica de tutela individual que não desconsidere a sua essência massificada. Acerca disso, um dos autores deste artigo pôde desenvolver com maior vagar em dois outros trabalhos, aos quais remetemos o leitor ${ }^{38}$. Em outras palavras, a busca pela aderência entre a técnica processual e o direito material não pode, por um lado, desconsiderar a homogeneidade dos direitos plurindividuais, mas tampouco deve, por outro, pretender eliminar a individualidade existente ${ }^{39}$.

Defendant Class Actions, Verbandsklage etc; e c) em massa ou de alta intensidade: embasadas prioritariamente em direitos individuais homogêneos que dão margem à propositura de ações individuais repetitivas ou seriais, que possuem como base pretensões isomórficas, com especificidades, mas que apresentam questões (jurídicas e/ou fáticas) comuns para a resolução da causa." [...] "esses singelos exemplos somente demonstram a necessidade de trato diferenciado dos litígios seriais, uma vez que não é possível resolver tal litigiosidade individual residual, mesmo que exista um dimensionamento técnico adequado dos processos coletivos, uma vez que cidadãos ainda continuarão a propor suas demandas para defesa de seus direitos individuais (mesmo que coletivos lato sensu).

${ }^{35}$ BEDAQUE, José Roberto dos Santos. Direito e processo: influência do direito material sobre o processo. $5^{\text {a }}$ ed. rev. ampl. São Paulo: Malheiros, 2009. p. 15.

${ }^{36}$ Ibid. p. 15.

${ }^{37}$ DANTAS, Bruno. Teoria dos Recursos Repetitivos: tutela pluri-individual nos Recursos Dirigidos ao STF e ao STJ (art. 543-B e 543-C do CPC). São Paulo: Editora Revista dos Tribunais), 2014. p. 46.

38 DANTAS, Bruno. Jurisdição coletiva, ideologia coletivizante e direitos fundamentais. Revista de Processo, v. 251, p. 341-358, 2016. DANTAS, Bruno. Teoria dos Recursos Repetitivos: tutela pluriindividual nos Recursos Dirigidos ao STF e ao STJ (art. 543-B e 543-C do CPC). São Paulo: Editora Revista dos Tribunais), 2014.

${ }^{39}$ Cabe reforçar o argumento aqui. As primeiras formulações do processo coletivo no Brasil pretenderam trilhar exatamente a senda da supressão da individualidade, em nome de uma proteção jurisdicional genérica. Adeptos dessa linha doutrinária defendem a restrição do acesso individual à justiça como maneira de fomentar a utilização do processo coletivo. Esse modelo organicista e autoritário é incompatível com a estrutura liberal do nosso Estado. Ainda que tenhamos consagrado direitos sociais, esse só fato não autoriza a compreensão de que teríamos abandonado a concepção liberal de respeito e proteção ao indivíduo em troca da organicista, que atribui ao Estado o papel de grande tutor da sociedade, quase um grande irmão. 
Como se vê, é um equilíbrio difícil, mas, em nosso entendimento, possível.

Ao nosso ver, a experiência global com as ações coletivas provou uma enorme dificuldade em manter o equilíbrio dessa equação, do que resultou diretamente uma inclinação para os procedimento modelo ou causa-piloto que despontaram na Europa e que, mais tarde, serviram de inspiração para o legislador do CPC de 2015.

\section{Declínio das class actions e surgimento dos "procedimentos modelo" e "casos-} piloto": aperfeiçoamento da tutela de massa à heterogeneidade substancial das pretensões individuais

A adoção, pelo Código de Processo Civil de 2015, da ferramenta do Incidente de Resolução de Demandas Repetitivas, representa um grande passo em favor da adequação da técnica processual de massa em relação às particularidades dos direitos individuais.

Nas contribuições doutrinárias que vêm sendo feitas desde antes da promulgação da versão final do código, um aspecto específico do procedimento parece ter absorvido a atenção dos estudiosos: a relação desse novo mecanismo com a aproximação entre $o$ civil law e o common law, do que decorreria uma alteração das noções tradicionais de fonte do direito que o primeiro há muito concebia, e isso estaria expresso no art. 927 do CPC.

Não nos cabe aqui descer a fundo na discussão. Basta consignar que entendemos não dispor o CPC de um verdadeiro sistema de precedentes - como tem o common law -, senão de "precedentes à brasileira". ${ }^{40}$ A eficácia vinculante das decisões do art. 927 do CPC não significa necessária transmutação do sistema de civil law. O common law também tem demonstrado apreço pela escrituração de regras sem que isso signifique um necessário amálgama com o civil law. A recíproca é verdadeira, mas para confirmar que por detrás da mutualidade o que há é uma necessidade de racionalizar o direito com técnicas que se provaram úteis ${ }^{41}$, e não uma sobreposição de culturas.

\footnotetext{
${ }^{40}$ ARRUDA ALVIM, Teresa; DANTAS, Bruno. Recurso especial, recurso extraordinário e a nova função dos tribunais superiores. 6a ed. São Paulo: Revista dos Tribunais, 2019. p. 273.

${ }^{41}$ Cf. FUX, Luiz. O novo processo civil. Rev. TST, Brasília, vol. 80, no 4, out/dez 2014, p. 276: “Ademais, com o decorrer do tempo veio a acontecer o que Chiovenda preanunciara no primeiro quartel do século passado, vale dizer, a evolução do processo civil restaria por unir as famílias do civil law e da common law, permitindo uma interação capaz de institutos de um sistema serem úteis ao outro. Aliás, ao longo das últimas décadas, os sistemas romano-germânico e anglo-saxônico vêm emprestando um ao outro a sua experiência. Assim é que o Brasil, país de tradição legalista, vem se curvando à força dos precedentes judiciais tão íntimos do sistema
} 
Particularidade que, a nosso ver, pareceu sobreposta pelo entusiasmo generalizado com a doutrina dos precedentes, foi a experiência das class actions no que toca à tutela massificada de direitos individuais e sua influência na adoção dos mecanismos de tutela pluri-individual, não só no Brasil, mas no mundo.

No que toca o objeto deste artigo, devemos salientar que o surgimento desse tipo de tutela é resultado de uma necessidade de conferir melhor adequação da tutela processual à particularidade dos direitos individuais em contextos de lides massificadas.

No Brasil, para dar cabo a um problema generalizado de litigiosidade de massa, adotamos como inspiração técnicas processuais que foram criadas para solucionar situações específicas de litigiosidade de massa (Musterverfahren e Group Litigation Order). No entanto, pouco nos perguntamos por que razão o direito alemão e o direito inglês, nos quais buscamos a inspiração de nossa técnica, não se valeram de suas respectivas ações coletivas, ou demais mecanismos de tutela coletivizada, para solucionar as milhares de demandas que justificaram a criação daqueles procedimentos.

Arriscamos o seguinte: tais ferramentas são uma resposta direta à dificuldade das class actions de oferecerem uma solução massificada capaz de prestigiar, sem supressões, a autonomia individual na tutela massificada dos direitos individuais homogêneos - o que ficou evidente na experiência norte-americana com as class actions indenizatórias ${ }^{42}$.

A história recente das class actions tem como marco divisor um julgamento da Suprema Corte norte-americana de 1999: o caso Anchem Products, Inc. v. Windsor ${ }^{43}$.

Já tivemos a oportunidade de dissertar com maior vagar sobre o tema em outra ocasião, mas, basicamente, o que se debateu ali foi a adequação de uma settlement class action aos requisitos estabulados pela Rule 23 das Federal Rules of Civil Procedure, tendo por pano de fundo um dano infligido a milhões de trabalhadores da indústria norte-americana pelo mineral amianto, o que atraía a responsabilidade de dezenas de empresas.

anglo-saxônico, fórmula apta a fazer justiça igual para cidadãos que estão na mesma situação jurídica; ao passo que a Inglaterra, desde 1999, país de tradição dos precedentes, adotou um complexo Código de Processo Civil (Rules of Civil Procedure)."

42 Aqui nos referimos tanto à class action for damages quanto à settlement class action.

43 Relevante para esse cenário, assim como Anchem Products, Inc. v. Windsor, foi também o caso Ortiz v. Fibreboard Corp, decidido em 1998 e que também versava sobre o problema do amianto. No entanto, fazemos opção por não explorá-lo aqui. Basta o registro de que aponta para as mesmas conclusões. 
Na década de 1960, esses trabalhadores começaram a demandar individualmente no Judiciário reclamando indenizações de alto valor pela exposição ao mineral, que era altamente cancerígeno. Falamos de um grupo potencial de 13 a 21 milhões de pessoas.

Naturalmente, o Judiciário norte-americano teve de cogitar alternativas para solucionar o fluxo inesgotável de demandas que ingressavam diariamente nas Cortes. A aposta inicial foram as ações coletivas: modificou-se a Rule 23 das Federal Rules of Civil Procedure, passando a se admitir a figura das class actions for damages (uma espécie de ação coletiva indenizatória, que antes não era possível, já que as class actions eram declarativas, constitutivas ou mandamentais) e o mecanismo do opt-out (que vincula à decisão coletiva aqueles que não optarem por se excluir do processo, mecanismo que, por sua vez, trabalha com a inércia, aumentando a extensão da classe exponencialmente em relação a classes $o p t-i n^{44}$ ).

Outra alternativa eram as settlement class actions, uma espécie de class action que busca a homologação de um acordo coletivo, muito utilizadas para as indenizações de massa. Outros mecanismos foram criados, como o multidistrict litigation $(M D L)$ e os bellwether trials. No entanto, pelo menos nesse primeiro momento, o carro-chefe do combate à litigiosidade eram as class actions indenizatórias.

Não tardou para que sérios problemas começassem a surgir, dos quais nos ocuparemos apenas de $u^{45}$ : os problemas de representação na tutela coletiva.

Pendentes as milhares de ações coletivas por todo os Estados Unidos pleiteando reparação pelos danos sofridos, foi instaurado um MDL para fins de consolidação das múltiplas ações em juízo único.

\footnotetext{
${ }^{44}$ Cf. DODSON, Scott. An opt-in Option for Class Actions. Michigan Law Review., vol. 115., issue 2., 2016. p. 184: "Opt-out classes, which include all members who do not opt out, tend to be more inclusive than opt-in classes, which include only members who affirmatively opt in. Because of inertia, an opt-in regime would result in "drastically reduce[d]" numbers of class members. An older empirical study from 1974 suggested that an opt-in mechanism would result in class sizes from around $40-70 \%$ smaller than opt-out classes. More recent studies have confirmed that an overwhelming percentage of class members - near 99\% - follows the default in opt-out classes, often making for very large classes. Size matters for all kinds of reasons. The economies of scale are greater in large classes, making smaller-value claims more viable and saving all parties and the courts from duplicative litigation."

${ }^{45}$ Para uma análise completa, ver MULLENIX, Linda S.. Ending Class Actions as We Know Them: Rethinking the American Class Action (June 21, 2014). 64 Emory Law Journal 399 (2014); U of Texas Law, Public Law Research Paper No. 565. Disponível em: https://ssrn.com/abstract=2457429. Acesso em: 26/04/2021. Esse artigo possui uma versão em português traduzida pelos autores deste artigo: MULLENIX, Linda. $O$ fim do processo coletivo tal como o conhecemos: repensando a class action norte-americana. Trad. Bruno Dantas. São Paulo: Revista dos Tribunais, v. 283, ano 43, set./ 2018.
} 
Rio de Janeiro. Ano 15. Volume 22. Número 3. Setembro a Dezembro de 2021

Periódico Quadrimestral da Pós-Graduação Stricto Sensu em Direito Processual da UERJ

Patrono: José Carlos Barbosa Moreira (in mem.). ISSN 1982-7636. pp. 143-169

www.redp.uerj.br

Uma vez consolidadas as ações, deu-se início às tratativas para se tentar chegar a um acordo global (global settlement, que é um acordo destinado a pôr um fim definitivo à responsabilidade do réu). As negociações foram conduzidas pelas partes e advogados nomeados como representantes do descomunal, em extensão, grupo de lesados, tanto em nome daqueles que já tinham ajuizado ações quanto daqueles em quem os efeitos do amianto ainda não tinham se evidenciado e, portanto, sequer haviam procurado o Judiciário.

Das tratativas resultou um esquema indenizatório, submetido à apreciação do Judiciário por meio de uma settlement class action, que dividia os elegíveis para reparação em quatro categorias: (i) pessoas que adquiriram mesotelioma; (ii) pessoas que adquiriram câncer de pulmão; (iii) pessoas que adquiriram outros tipos de câncer (como, por ex., câncer de esôfago, estômago, etc.) e; (iv) pessoas que adquiriram "non-malignant condition" (como, por ex., asbestose).

Também integrava os termos do acordo que (i) pessoas que eventualmente ainda não tivessem desenvolvido qualquer doença poderiam, se habilitar dentro das quatro categorias quando ela viessem a se manifestar; que (ii) o fundo criado para a indenização dos prejudicados ficaria disponível por dez anos e não seria atualizado conforme a inflação; $e$ que (iii) aqueles que não se inserissem nas quatro categorias iriam receber um valor préfixado $^{46}$.

Em primeira instância, a Corte chancelou o acordo, certificou a demanda coletiva, ao argumento de que ela satisfazia os requisitos da Rule 23, muito embora tenha sofrido inúmeras objeções, que alegavam a existência de um conflito de interesse entre os membros do grupo, notadamente entre aqueles em que os efeitos do amianto já haviam se manifestado e aqueles em que os efeitos ainda não haviam se manifestado.

A Corte de Apelações, por sua vez, entendeu que os interesses dos membros ausentes (aqueles que não haviam ainda ajuizado suas ações e aqueles que embora o tenham feito não foram devidamente considerados na negociação) não foram adequadamente representados,

\footnotetext{
${ }^{46}$ KLONOFF, Robert. H; BILICH, Edward K.M; MALVEAUX, Suzette M. Class actions and other multiparty litigation: cases and materials. American casebook series. 2 ed. Thomson West: 2006, p. 675: "The stipulation descibes four categories of compensable disease: mesothelioma; lung câncer; certain 'other cancers' (colon-rectal, laryngeal, esophageal, and stomach cancer); and 'mon-malignant conditions' (abestosis and bilateral pleural thickening). Persons with 'exceptional' medical claims - claims that do not fall within the four described diagnostic categories - may in some instances qualify for compensation, but the settlement caps the number of 'exceptional' claims CCR must cover”.
} 
não atendendo ao requisito da adequacy da Rule 23 , negando certificação à class action, que havia sido concedida em primeiro grau.

Levada a questão à apreciação da Suprema Corte, esta confirmou a decisão da Corte de Apelações, argumentando, em síntese, que "The settling parties, in sum, achieved a global compromisse with no structural assurance of fair and adequate representation for the diverse groups and individuals affected. ${ }^{47 "}$ E reconheceu que a class action não conseguiu satisfazer aos requisitos de predominância da questão comum (predominance) e da representação adequada (adequacy of representation), pois o grupo possuía inúmeras particularidades em virtude dos tipos de efeitos colaterais sofridos, do que decorriam múltiplas pretensões com interesses divergentes, como era o caso daqueles que já haviam sido afetados negativamente pelo amianto (currently injured claimants) e aqueles em que os efeitos ainda não haviam se evidenciado (exposure-only claimaints).

Ora, o primeiro grupo, mal ou bem ouvido pelos representantes que negociaram os acordos, naturalmente desejava obter as indenizações mais generosas possíveis; o segundo grupo, sem voz alguma, desejava que essa indenização fosse a mais justa possível ${ }^{48}$ (pois era inevitável a alocação de custos que terminaria por retirar deles justas indenizações no futuro), ou que o fundo ficasse disponível por mais tempo, ou que fosse, no mínimo, corrigido monetariamente, ou que o valor pré-fixado para quem não se inserisse nas categorias indicadas pudesse ser melhor avaliado conforme cada caso.

Fato é que os negociadores do acordo coletivo entabulado na class action, praticamente, escolheram um time ${ }^{49}$. E, ao fazê-lo, ignoraram inúmeras particularidades de outras pretensões individuais que teriam direito de ser melhor consideradas se não fossem coletivizadas. Não obstante, ainda que a ação coletiva fosse a julgamento, como se fosse uma class action for damages pura, a sentença dificilmente conseguiria endereçar em totalidade, sem supressões, a diversidade de pretensões envolvidas em um grupo tão extenso como o que se tinha ali. Qualquer delimitação de categorias - conquanto busque prestigiar

\footnotetext{
${ }^{47}$ KLONOFF, Robert., Op. cit. p. 681.

${ }^{48}$ Ibid. p. 681:"In significant respects, the interests of those within the single class are not aligned. Most saliently, for the currently injured, the critical goal is generous immediate payments. That goal tugs against the intereset of exposure-only plantiffs in ensuring na ample, inflation-protected fund for the future."

${ }^{49}$ Ibid, p. 681: "As the Third Circuit pointed out, named parties with diverse medical conditions sought to act on behalf of a single giant class rather than on behalf of discrete subclassses. In significant respects, the interests of those within the single class are not aligned.
} 
Revista Eletrônica de Direito Processual - REDP.

Rio de Janeiro. Ano 15. Volume 22. Número 3. Setembro a Dezembro de 2021

Periódico Quadrimestral da Pós-Graduação Stricto Sensu em Direito Processual da UERJ

Patrono: José Carlos Barbosa Moreira (in mem.). ISSN 1982-7636. pp. 143-169

www.redp.uerj.br

as subclasses - corre o risco de deixar alguém de fora, ou de que seja induzida por representantes que não tenham suficiente unidade de interesses com as subclasses a legitimar a submissão destas últimas às suas decisões ${ }^{50}$, como foi o caso do esquema reparatório do caso em questão.

Esse julgamento, que resultou na anulação de um acordo avaliado em 1.3 bilhões de dólares, que recompensaria imediatamente mais de 100 mil pessoas, enviou uma mensagem bem clara para o mundo: o Estado não está autorizado a fazer política judiciária ceifando direitos individuais, e as ações coletivas, quando destinadas à tutela de direitos individuais homogêneos, criam sérios riscos de que isso aconteça. Não à toa, mais tarde, Linda Mullenix vai propor a extinção da class action for damages ${ }^{51}$.

Não são poucos os que escrevem acerca da tutela jurisdicional no mundo após Anchem Products, Inc. v. Windsor ${ }^{52}$. Em reação a esse julgamento é que a Europa passou a adotar um modelo diferente para a tutela de direitos individuais homogêneos ${ }^{53}$ : os "procedimentos modelo" ou "causa-piloto", espécie do que chamamos de tutela pluriindividual, dos quais são expoentes o Musterverfahren alemão e a GLO inglesa.

Devemos destacar que os próprios Estados Unidos - e este é um ponto pouco explorado pelos estudiosos no Brasil -, depois desse julgamento, passaram a utilizar com

\footnotetext{
${ }^{50}$ Ibid, p. 681: "The adequacy inquiry under Rule 23 (a)(4) serves to uncover conflicts of interest between named parties and the class they seek to represent. '[A] class representative must be part of the class and 'possess the same intereset and suffer the same injury' as the class members."

${ }^{51}$ MULLENIX, Linda. O fim do processo coletivo tal como o conhecemos: repensando a class action norteamericana. Trad. Bruno Dantas. São Paulo: Revista dos Tribunais, v. 283, ano 43, set./ 2018.

${ }^{52}$ Cf. HENSLER, Deborah. As Time Goes By: Asbestos Litigation After Amchem and Ortiz. Texas Law Review., Austin Vol. 80, Ed. 7, (Jun 2002): 1899-1924. ISSACHAROFF, Samuel. Shocked: Mass Torts and Aggregate Asbestos Litigation after Amchem and Ortiz. 80 TEX. L. REV. 1925 (2002).

${ }^{53}$ Comentando a reação do sistema Europeu, Samuel Issacharoff e Geoffrey P. Miller relatam: (Will aggregate litigation come to Europe? Law \& Economics Research Papers Series. Working paper n. 08-46. Nov. 2008): "And, yet, one need spend only a few minutes in conversations with European reformers before the proverbial "but" enters the discourse: 'But, of course, we shall not have American-style class actions.' Rachel Mulheron, professora da Universidade de Londres, a esse respeito, anota: "Two reasons contributed to the implementation of group litigation order as the principal means by which to handle multi-party litigation in England, rather than the class action device. First, class action regimes are perceived to lack utility and flexibility. Secondly, unfavarouble comments have repeatedly been made in respect of the US class action regime. (grifos nossos). MULHERON, Rachel. The class action in common law legal systems: a comparative perspective. OxfordPorland: Hart Publishing, 2004, p. 68.
} 
Rio de Janeiro. Ano 15. Volume 22. Número 3. Setembro a Dezembro de 2021

Periódico Quadrimestral da Pós-Graduação Stricto Sensu em Direito Processual da UERJ

Patrono: José Carlos Barbosa Moreira (in mem.). ISSN 1982-7636. pp. 143-169

www.redp.uerj.br

mais frequência técnicas de tutela pluri-indvidual para a solução dos mass torts, a partir de uma solução que conjuga o Multidistrict litigation e os Bellwether trials ${ }^{54}{ }^{55}$.

O modelo procedimental desses mecanismos é concebido para evitar, ou no mínimo mitigar, os problemas que as ações coletivas atraem. Na tutela pluri-individual não se veda a ninguém a oportunidade de ajuizar sua demanda individual, com a sua respectiva definição particular e individualizada dos argumentos jurídicos e pedidos. $\mathrm{O}$ design procedimental dessas técnicas preserva a individualidade em meio à massa, aliando economia de escala ao direito de ação e ao devido processo legal.

\section{O Código de Processo Civil de 2015 na esteira de uma tendência global: o} Incidente de Resolução de Demandas Repetitivas como técnica mais promissora que as ações coletivas para a tutela dos direitos individuais homogêneos.

O Código de Processo Civil de 2015, ao adotar mecanismo inspirado no Musterverfahren alemão e na GLO inglesa, se coloca na esteira de uma tendência vanguardista ${ }^{56}$ que aprendeu com a experiência da tutela coletiva e que pretende não incorrer nos mesmos erros. Trata-se, o incidente de resolução de demandas repetitivas - conquanto ainda lhe possam ser feitas certas críticas $^{57}$ - de uma ferramenta sofisticada, capaz de conferir à tutela massificada dos direitos individuais homogêneos uma aderência ao direito material superior à que as ações coletivas que perseguem o mesmo fim se mostraram capazes, pois neste mecanismo, o IRDR, quem define os contornos do litígio são os próprios

\footnotetext{
${ }^{54}$ A terceira edição de uma das principais obras de Linda Mullenix (Mass Tort Litigation: Cases and Materials (3d ed.), base da disciplina que leciona na Universidade do Texas, reflete essas mudanças. Cf: "This third edition of Mass Tort Litigation is revised to reflect developments in mass tort litigation in the decade since the second edition. The revised text addresses mass tort class litigation in a post-Amchem/Ortiz world. New materials have been added concerning expanded use of MDL auspices, bellwether trials, non-class aggregate settlements, the quasi-class action, the aggregate settlement rule, and the ethical duties of attorneys with clients in MDL and non-class proceedings." [...] Disponível em: <https://law.utexas.edu/faculty/publications/2017-Mass-Tort-Litigation-Cases-and-Materials〉. (grifamos)

55 THE AMERICAN LAW INSTITUTE. Princípios do Direito: Processo Agregado. Trad. Bruno Dantas. 1. ed. - São Paulo: Editora Revista dos Tribunais, 2017, p.

${ }^{56}$ MENDES, Aluísio Gonçalves de Castro. Incidente de resolução de demandas repetitivas: sistematização, análise, e interpretação do novo instituto processual. Rio de Janeiro: Forense, 2017, p. 27-37.

57 ABBOUD, Georges. CAVALCANTI, Marcos de Araújo. Inconstitucionalidades do incidente de resolução de demandas repetitivas (IRDR) e os riscos ao sistema decisório. Revista de Processo, vol. 240., 2015 , p. $221-242$.
} 
Rio de Janeiro. Ano 15. Volume 22. Número 3. Setembro a Dezembro de 2021

Periódico Quadrimestral da Pós-Graduação Stricto Sensu em Direito Processual da UERJ

Patrono: José Carlos Barbosa Moreira (in mem.). ISSN 1982-7636. pp. 143-169

www.redp.uerj.br

indivíduos prejudicados, e não algum representante coletivo, que nem sempre conhece bem ou sequer concorda com os interesses daqueles que representa ${ }^{58}$.

Tradicionalmente, existiam apenas duas formas de tutelar os direitos individuais homogêneos em juízo: ou permitir que eles fossem pleiteados pessoalmente por seus titulares, mediante ações individuais, ou por um agente a que a lei outorgasse legitimidade para realizar essa representação. Essa é, ainda, a realidade da tutela coletiva no Brasil, que fez opção pelo último modelo, guiado por um representante.

No entanto, o fato de o primeiro modelo ser impraticável não faz do segundo o modelo ideal. Inúmeros problemas de representação são apontados pela doutrina ${ }^{59}$.

Por ter adotado um modelo ope legis de controle da representação, ao invés do ope iudicis norte-americano, a legislação brasileira não exige que o representante coletivo, ao propor uma ação coletiva para a tutela de direitos individuais homogêneos, demonstre concretamente sua capacidade para adequadamente representar o grupo, sendo esta presumida quando a ação coletiva preenche as - pouco rigorosas - condições legais. Isso faz o nosso controle de representação ser bem menos rigoroso do que o norte-americano, assimetria que se justifica pelo fato de as class actions, nos EUA, terem o condão de fazer coisa julgada pro et contra (a favor ou contra as partes processuais), o que não ocorre no Brasil, pois optou-se, aqui, pelo modelo de coisa julgada secundum eventum litis, isto é, em que a coisa julgada não se forma em desfavor dos autores se julgada improcedente a ação.

Naturalmente, nosso modelo abre espaço para representações inábeis e defeituosas, ou, o que é pior, por atores que, ainda que habilmente postulando em juízo, não consultam os interesses daqueles que serão atingidos pelos efeitos da decisão. Disso resulta que uma sentença de procedência proferida em uma ação coletiva pode, sim, prejudicar os indivíduos

\footnotetext{
${ }^{58}$ ANDREWS, Neil. Multi-party proceedings in England: representative and group actions. Duke joumal of Comparative and Intemational Law 11, 2001, p. 260: "Therefore, group actions involve positive opting-in, or at least a positive decision to litigate. This contrasts with representative proceedings where no such positive decision is necessary. Representative proceedings can effectively take place behind the backs of class members without their knowledge, participation, or control."

59 ARENHART, Sérgio Cruz. Processo multipolar, participação e representação de interesses concorrentes. p. 423- 449. In: ARENHART, Sérgio Cruz; JOBIM, Marco Félix (Org.). Processos estruturais. Salvador: Juspodvim, 2017, p. 426. VITORELLI, Edilson. O devido processo legal coletivo: dos direitos aos litígios coletivos. São Paulo: Editora Revista dos Tribunais, 2016. p. 330.
} 
a que se destina. Basta que não reflita seus reais interesses. Barbosa Moreira já percebia e destacava esse problema na década de $1980^{60}$.

Evidentemente, o IRDR não sana os problemas de representação da tutela coletiva nem está, ele próprio, de todo isento de críticas quanto à representatividade-, mas cria uma nova alternativa à tutela dos direitos individuais homogêneos, uma que prestigia a natureza heterogênea das pretensões individuais e a análise das especificidades de cada demanda ${ }^{61}$, já que a coletivização não ocorre antes do exercício do direito de ação pelos indivíduos, mas depois, de forma incidental ${ }^{62}$ e apenas para a definição da questão comum de direito.

Poder-se-ia dizer que entre a tutela individual e a tutela coletiva, o IRDR segue o caminho do meio, propondo uma solução que preserva a autonomia na definição dos contornos do litígio pelos próprios titulares do direito e, ao mesmo tempo, viabilizando uma resolução massificada com a definição abstrata da questão comum de direito. Nisto está uma das grandes contribuições do CPC de 2015 para a efetivação do sistema de justiça.

Assim, dilata-se a caixa de ferramentas da tutela dos direitos individuais homogêneos. Se, tradicionalmente estes dispunham dos dois caminhos procedimentais acima mencionados, o CPC de 2015 aí inseriu mais um: o IRDR, que tem o mérito de reunir a habilidade de prover uma alternativa eficiente à impraticável resolução caso-por-caso das demandas repetitivas - promessa não (ou mal) cumprida pelas ações coletivas - sem, no entanto, incorrer no problema de homogeneização artificial dos direitos individuais que, não raro, macula a tutela jurisdicional, ainda que bem intencionada, promovida pela ação coletiva para a tutela de direitos individuais homogêneos.

Por último, cabe um esclarecimento. Tradicionalmente se sustenta que a relação entre o IRDR e a ação coletiva para a tutela dos direitos individuais homogêneos é de complementaridade ${ }^{63}$.

\footnotetext{
${ }^{60}$ BARBOSA MOREIRA, José Carlos. Temas de Direito Processual Civil: terceira série. São Paulo: Editora Saraiva, 1984, p. 190.

61 "A divisão da cognição, que o incidente [Musterverfahren] viabiliza, mitiga os problemas de análise das especificidades de cada demanda e viabiliza um melhor julgamento dos aspectos "idênticos" das ações seriais. Tal exemplo não deve ser obviamente transportado ao direito brasileiro sem maiores reflexões, mas representa um exemplo de busca de dimensionamento do problema das ações repetitivas sem negligenciar as garantais processuais do modelo constitucional de processo." NUNES, Op. cit. p. 48.

${ }^{62}$ PINHO, Humberto Dalla Bernadina de; PORTO, José Roberto Mello. Manual de tutela coletiva. 1 ed. São Paulo: Saraiva, 2021.

${ }^{63}$ MENDES, Aluisio Gonçalves de Castro; SILVA, Larissa Clare Pochmann da. Op. cit. p. 158.
} 
Revista Eletrônica de Direito Processual - REDP.

Rio de Janeiro. Ano 15. Volume 22. Número 3. Setembro a Dezembro de 2021

Periódico Quadrimestral da Pós-Graduação Stricto Sensu em Direito Processual da UERJ

Patrono: José Carlos Barbosa Moreira (in mem.). ISSN 1982-7636. pp. 143-169

www.redp.uerj.br

Entendemos que essa complementariedade existe no que tange a tutela de direitos individuais homogêneos que envolvam pretensões de baixo valor (negative value claims) ${ }^{64}$. Isso porque tais pretensões esbarram em barreiras organizacionais ${ }^{65}$ que levam seus titulares, em um juízo de custo-benefício, a entenderem não valer a pena ajuizar uma ação para perseguir seus direitos em juízo ${ }^{66}$.

Neste aspecto, as ações coletivas exercem formidável papel que o IRDR não poderia exercer, já que atua na via incidental, pressupondo o exercício do direito de ação. É apenas no que diz respeito à tutela de direitos individuais homogêneos em que se esteja em questão pretensões de expressivo valor (positive value claims), que sustentamos haver, em favor do IRDR, superioridade em relação à ação coletiva que persiga o mesmo objeto.

Quanto a essa última espécie de pretensão o IRDR, mais do que técnica complementar, é o procedimento adequado de tutela, já que resguarda a esfera de autonomia individual dos titulares do direito onde a representação coletiva já provou atrair sérios riscos de supressão.

Em síntese, o que vislumbramos é uma relação mista entre ambas as técnicas na tutela de direitos individuais em lides massificadas: por um lado, de complementariedade para a tutela de pretensões inexpressivas, por outro, de superioridade para a tutela de pretensões suficientemente expressivas a justificar o exercício do direito de ação.

\footnotetext{
${ }^{64}$ Negative value claims e positive value claims é uma nomenclatura muito utilizada pela doutrina do direito processual coletivo norte-americana, já mais habituada com essa diferenciação. Para um estudo completo, ver HYLTON, Keith. N. Deterrence and Aggregate Litigation. Boston Univ. School of Law, Law and Economics Research Paper No. 17-45: "Usefully, class action lawsuits have been put into two categories: those consisting of negative expected value claims, where the expected individual recovery would be less than the claimant's cost of litigation (for example, consumer claims), and those consisting of positive expected value claims (for example, securities claims).

${ }^{65}$ Falando em “obstáculo organizacional”, Cappelleti (O acesso à justiça e a função do jurista em nossa época. Revista de Processo. vol. 61. p. 144. Jan / 1991, p. 5): “O consumidor que tenha sofrido um leve dano por causa de um produto defeituoso ou por um defeito de confecção ou de embalagens do produto adquirido, normalmente não tenha suficiente motivação, informação, força econômica para levar a Juízo o poderoso produtor, o "mass-wrongdoer"; e ainda que o fizesse, o resultado de sua vitória seria irrisório e certamente não teria a eficácia decorrente da representatividade que pudesse impedir o produtor de continuar tranqüilamente com suas atividades." [...] No plano individual, este tipo de interesse resta, praticamente, privado de tutela eficaz. A exigência tem sido aquela de se "organizar" tais interesses, de dar um "autor" - um "ator ideológico" (ideological plaintiff) a estes interesses."

66 Como explica Judith Resnik, as class action é um mecanismo criado pelo Estado para subsidiar a judicialização de pretensões que, do contrário, não encontrariam incentivos econômicos suficientes para serem levadas ao Judiciário (Money matters: judicial Market interventions creating subsidies and awarding fees and costs in individual and aggregate litigation. University of Pennsylvania Law Review. vol. 148, p. 21192000 .
} 


\section{3) Considerações finais}

Procurou-se demonstrar que quatro, pelo menos, foram os fatores que pavimentaram o caminho para a adoção do Incidente de Resolução de Demandas Repetitivas pelo legislador do CPC de 2015: (i) a mudança de paradigma quanto ao fundamento individualista do direito processual civil clássico; (ii) o movimento do acesso à justiça; (iii) o movimento das tutelas diferenciadas; e (iv) a experiência norte-americana com o declínio da class actions indenizatórias.

Todos os fatores, conquanto guardem suas diferenças e atuem, alguns deles, em planos até mais abrangentes do processo civil, exerceram influência na técnica processual de modo a encaminhá-la para um perfil cada vez mais rente à realidade do direito material que, mais tarde, foi culminar na adoção do IRDR pelo CPC de 2015. Este é resultado um constante esforço doutrinário e de experiências bem-sucedidas e fracassadas que permitiram o amadurecimento da certeza que o modelo procedimental da tutela pluri-individual era o mais adequado para lidar com os direitos individuais homogêneos.

Essa preferência, como se explicou, se deve ao fato de que a tutela pluri-individual oferece ferramental mais promissor do ponto de vista da aderência da técnica processual à realidade substancial dos direitos do que a tutela coletiva que persegue o mesmo objeto. Isto porque, no IRDR, quem define os contornos do litígio são os próprios titulares da relação jurídica de direito material, e não eventual legitimado coletivo, que nem sempre conhece bem ou concorda com os verdadeiros interesses daqueles em nome de quem atua. Com o IRDR, é possível obter a eficiência prometida pelas ações coletivas para a tutela dos direitos individuais homogêneos evitando-se, porém, incidir no problema da homogeneização artificial de pretensões de que as últimas provaram padecer, como se demonstrou com as críticas feitas à experiência norte-americana e brasileira.

Ao final, sustentamos haver entre o IRDR e ação coletiva para a tutela de direitos individuais homogêneos uma relação mista: por um lado, de complementariedade para a tutela de pretensões inexpressivas, por outro, de superioridade do IRDR para a tutela de pretensões suficientemente expressivas a justificar o exercício do direito de ação.

Por fim, deve-se enfatizar que o fato de concordarmos que o CPC de 2015 deu um grande passo em favor de um sistema de justiça mais efetivo não autoriza a conclusão de 
que pensemos ser o IRDR uma técnica isenta de defeitos. Estes existem, e são objeto de críticas, algumas com mais, outras com menos razão. Abordá-las, porém, fugiria aos estreitos limites deste trabalho. Basta consignar que o passo é importante, e que, com a consolidação de novas premissas, como a da tutela pluri-individual, não tardarão seguir os aperfeiçoamentos, como é de costume nos anos que sucedem as codificações.

\section{REFERÊNCIAS}

ABBOUD, Georges. CAVALCANTI, Marcos de Araújo. Inconstitucionalidades do incidente de resolução de demandas repetitivas (IRDR) e os riscos ao sistema decisório. Revista de Processo, vol. 240., 2015.

ANDREWS, Neil. Multi-party proceedings in England: representative and group actions. Duke joumal of Comparative and Intemational Law 11, 2001.

ALEXY, Robert. Teoria dos Direitos Fundamentais. Trad. Virgílio Afonso da Silva. São Paulo: Malheiros, 2008.

ARENHART, Sérgio Cruz. Processo multipolar, participação e representação de interesses concorrentes. p. 423- 449. In: ARENHART, Sérgio Cruz; JOBIM, Marco Félix (Org.). Processos estruturais. Salvador: Juspodvim, 2017.

ARRUDA ALVIM, José Manoel de. Anotações sobre as perplexidades e os caminhos do processo civil contemporâneo. Disponível em http://bit.ly/1ba78kp. Acesso em $\underline{13 / 4 / 2021}$,

ARRUDA ALVIM, Teresa; DANTAS, Bruno. Recurso especial, recurso extraordinário e a nova função dos tribunais superiores. 6a ed. São Paulo: Revista dos Tribunais, 2019.

BARBOSA MOREIRA, José Carlos. A ação popular do direito brasileiro como instrumento de tutela jurisdicional dos chamados "interesses difusos". In Temas de direito processual civil. São Paulo: Saraiva, 1977.

Ações coletivas na Constituição de 1988. Revista de Processo, São Paulo: Editora Revista dos Tribunais, v. 16, n. 61, jan./mar. 1991.

. Temas de Direito Processual Civil: terceira série. São Paulo: Editora Saraiva, 1984. 
BASTOS, Fabrício Rocha. Interface entre o CPC 15 e os Processos Coletivos. Revista do

Ministério Público do Rio de Janeiro no 70, out./dez. 2018.

BEDAQUE, José Roberto dos Santos. Direito e processo: influência do direito material sobre o processo. $5^{\text {a }}$ ed. rev. ampl. São Paulo: Malheiros, 2009.

BOBBIO, Norberto. A era dos direitos. Trad. Carlos Nelson Coutinho. Rio de Janeiro: Elsevier, 1992.

BONAVIDES, Paulo. Do Estado liberal ao Estado social. 8. ed. São Paulo: Malheiros, 2007.

CANOTILHO, J. J. Gomes. Constituição e défice procedimental. In Estudos sobre direitos fundamentais. $1^{\mathrm{a}}$ ed. São Paulo: RT, 2008.

CAPPELLETI, Mauro. O acesso à justiça e a função do jurista em nossa época. Revista de Processo. vol. 61, 1991.

La tutela degli interessi diffusi nel diritto comparato: con particolare riguardo

alla protezione dell'ambiente e dei consumatori. Milano: Giuffrè, 1976, p. VII.

Vindicating the Public Interest through the Court's (1976) 25 Buffalo Law

Review, 649, number 3, article 2.

CAPPELlETTI, Mauro; GARTH, Bryant. Acesso à Justiça. Tradução Ellen Gracie Northfleet. Porto Alegre: Fabris, 1988..

CHAYES, Abram. The Role of the Judge in Public Law Litigation. 89 HARV. L. REV. $1281,1976$.

DANTAS, Bruno. Jurisdição coletiva, ideologia coletivizante e direitos fundamentais. Revista de Processo, v. 251, p. 341-358, 2016.

. Teoria dos Recursos Repetitivos: tutela pluri-individual nos Recursos Dirigidos

ao STF e ao STJ (art. 543-B e 543-C do CPC). São Paulo: Editora Revista dos Tribunais), 2014

DODSON, Scott. An opt-in Option for Class Actions. Michigan Law Review., vol. 115., issue 2., 2016.

FUX, Luiz. O novo processo civil. Rev. TST, Brasília, vol. 80, no 4, out/dez 2014.

GRINOVER, Ada Pellegrini. Ensaio sobre a processualidade: fundamentos para uma nova teoria geral do processo. Brasília: Gazeta Jurídica, 2016. 
HENSLER, Deborah. As Time Goes By: Asbestos Litigation After Amchem and Ortiz.

Texas Law Review., Austin Vol. 80, Ed. 7, (Jun 2002): 1899-1924.

HYLTON, Keith. N. Deterrence and Aggregate Litigation. Boston Univ. School of Law,

Law and Economics Research Paper No. 17-45:

ISSACHAROFF, Samuel. Shocked: Mass Torts and Aggregate Asbestos Litigation after Amchem and Ortiz. 80 TEX. L. REV. 1925 (2002).

ISSACHAROFF, Samuel; MILLER, Geoffrey P. Will aggregate litigation come to Europe? Law \& Economics Research Papers Series. Working paper n. 08-46. Nov. 2008)

KLONOFF, Robert. H; BILICH, Edward K.M; MALVEAUX, Suzette M. Class actions and other multi-party litigation: cases and materials. American casebook series. 2 ed. Thomson West: 2006.

MENDES, Aluisio Gonçalves de Castro. Incidente de resolução de demandas repetitivas: sistematização, análise, e interpretação do novo instituto processual. Rio de Janeiro: Forense, 2017.

MENDES, Aluisio Gonçalves de Castro; SILVA, Larissa Clare Pochmann da. Ações Coletivas e incidente de resolução de demandas repetitivas: algumas considerações sobre a solução coletiva de conflitos. RJLB, Ano 3, 2017., nº 1.

MULHERON, Rachel. The class action in common law legal systems: a comparative perspective. Oxford-Porland: Hart Publishing, 2004

MULLENIX, Linda. O fim do processo coletivo tal como o conhecemos: repensando a class action norte-americana. Trad. Bruno Dantas. São Paulo: Revista dos Tribunais, v. 283 , ano 43 , set./ 2018.

NUNES, Dierle. Novos rumos para as tutelas diferenciadas no Brasil? In: THEODORO JÚNIOR, Humberto; LAUAR, Maira Terra. Tutelas diferenciadas como meio de incrementar a efetividade da prestação jurisdicional. Rio de Janeiro: GZ Editora, 2011.

PINHO, Humberto Dalla Bernardina de. A releitura do princípio do acesso à justiça e o necessário redimensionamento da intervenção judicial na resolução dos conflitos na contemporaneidade". In Revista Jurídica Luso-brasileira. Ano 5. Número 3. 2019. PINHO, Humberto Dalla Bernadina de; PORTO, José Roberto Mello. Manual de tutela coletiva. 1 ed. São Paulo: Saraiva, 2021. 
PISANI, Andrea Proto. Tutela giurisdizionale differenziata del lavoro. Milano: Giuffré, 1977.

RAWLS, John. Uma teoria da justiça. Trad. Almiro Pisetta e Lenita M. R. Esteves. São Paulo: Martins Fontes, 1997.

RESNIK, Judith. Managerial Judges. 96 Harv. L. Rev. 374, 448, 1982.

SCHENK, Leonardo Faria. Contraditório e cognição sumária. Revista eletrônica de direito processual. v. 13, n. 13, 2014.

SILVA, Ovídio A. Batista. Processo e ideologia: o paradigma racionalista. Rio de Janeiro: Forense, 2004.

THE AMERICAN LAW INSTITUTE. Princípios do Direito: Processo Agregado. Trad. Bruno Dantas. 1. ed. - São Paulo: Editora Revista dos Tribunais, 2017.

VILLEY, Michel. A formação do pensamento jurídico moderno. Trad. Claudia Berliner. São Paulo: Martins Fontes, 2005.

VITORELLI, Edilson. O devido processo legal coletivo: dos direitos aos litígios coletivos.

São Paulo: Editora Revista dos Tribunais, 2016. 